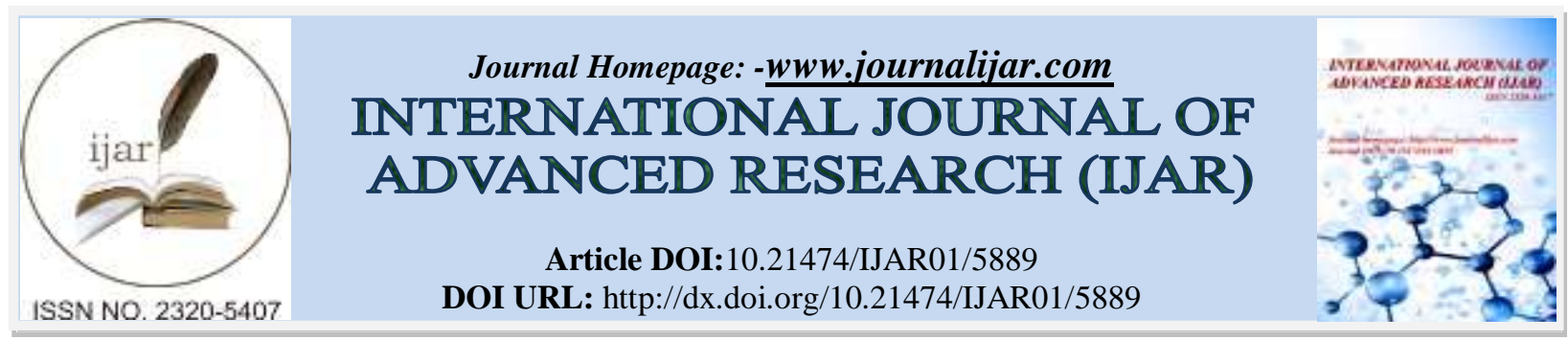

RESEARCH ARTICLE

\title{
RETROSPECTIVE ANALYSIS OF SURGICAL TREATMENT OF CAROTID BODY TUMOUR-AN INSTITUTIONAL EXPERIENCE.
}

\section{Dr. Mohanraja P, Dr. Sritharan N, Dr. Velladuraichi B, Dr. Ilayakumar P, Dr. JayanthV, Dr. Krishna M, Dr. Devarajan I, Dr. Prathapkumar S. and Dr. Murali M. \\ Institute of vascular surgery, Madras medical college, Chennai.}

\section{Manuscript Info}

Manuscript History

Received: 16 September 2017

Final Accepted: 18 October 2017

Published: November 2017

Key words:-

Carotid body tumor (CBT),

paragangliomas, surgical management.

\begin{abstract}
Aim: To analyse the demography, presentation, treatment modalities of carotid body tumour and evaluate outcomes and complications of surgical treatment of carotid body tumour .

Material And Methods: Twenty one patients CBT, treated surgically from January 2010 to December 2016 were included in the study. Patient demography, presentation, diagnostic modalities, surgical and radiological interventions, outcomes and complications were analysed.

Results: A total of 21 patients with age ranging from 13 to 60 years (median 45 years) with male preponderance (M:F=2.5:1) were diagnosed to have CBT in the study period. Local swelling was the commonest symptom $(\mathrm{n}=21)$, with other symptoms being hoarseness of voice, dysphagia, and ear/neck pain. Left laterality was found in $76.2 \%$ of patients $(\mathrm{n}=16)$, whereas $14.3 \%(\mathrm{n}=3)$ of them were right sided with 9.5\% $(\mathrm{n}=2)$ bilateral cases. Fifteen out of 21 patients $(71.4 \%)$ were classified as Shamblin's type II, with 2 of them (9.5\%) as type I and the remaining 4 patients (19\%) as type III CBTs. Thirteen patients underwent pre-operative angio-embolisation. Twenty patients (95.2\%) underwent complete excision, whereas one patient underwent partial excision. Operative site hematoma was the commonest post-operative complication encountered. All patients except the one with partial excision are asymptomatic with minimum of 6 months follow up.

Conclusion: Shamblin III had a high risk of postoperative neurovascular complications. Therefore, early detection and prompt surgical resection of CBTs will decrease surgical morbidity.
\end{abstract}

Copy Right, IJAR, 2017,. All rights reserved.

\section{Introduction:-}

Carotid body tumour (CBT) is a relatively rare vascular surgical pathology with incidence of 1 in 100000 in general population.Carotid body tumors (CBTs) are vascular tumors arising from paraganglionic cells of the carotid body which located in the posteromedial wall of the CCA at the carotid bifurcation. CBTs are most commonly found among paragangliomas that are typically located in four main sites in the head and neck: the carotid bifurcation (CBT), the foramen jugulare ,the middle ear cavity, and along the cervical portion of the vagus nerve. ${ }^{1}$

The diagnosis is based on clinical history, physical examination, imaging methods (such as ultrasound, computed tomography and magnetic resonance) and vascular evaluations (including angiography, tomographic angiography 
and magnetic resonance angiography). ${ }^{2}$ In this context, based on the Shamblin classification, Arya et al. used magnetic resonance imaging to pre-classify carotid body tumors before surgical treatment. ${ }^{3}$ This could improve preoperative management and reduce the complication rate. ${ }^{4}$

Surgery is the gold standard for curative treatment of CBTs. Gordon-Taylor ${ }^{5}$ described a safe, subadventitial dissection in 1940. Since the 1980s, devascularization of CBTs by ligation of feeding branches of the external carotid artery (ECA) during operation has been a common practical technique.Although advances in surgical techniques and the introduction of sensitive imaging modalities have significantly reduced mortality, the incidence of perioperative neurovascular complications, especially cranial nerve $(\mathrm{CN})$ deficit and intraoperative hemorrhage, remains considerable ${ }^{6,7}$. Some authors have justified using embolization because it reduces complications such as bleeding or neurological sequelae, ${ }^{8}$ although this procedure is not without its own inherent complications. ${ }^{9}$

Shamblin et al. proposed the classification of CBTs 1971, it has been widely used to describe the CBTs. Shamblin group I tumors are localized and do not involve the surrounding major vessels, group II are adherent or partially surround the vessels, and group III are large and encase the vessels. The size of tumor is positively correlated with the Shamblin classification because CBTs become more adherent to carotid vessels as they become larger ${ }^{10}$.The purpose of this study is to review our experience in the surgical management of CBTs and evaluate the outcomes and complications according to the Shamblin classification.

\section{Materials and methods:-}

This is a retrospective study based on patients with carotid body tumors who were treated at the Institute of vascular surgery, Madras medical college, Chennai. Twenty-one patients with carotid body tumour were evaluated and treated betweenJanuary 2010 to December 2016. The parameters analyzed were demography, symptoms, treatment and complications. The diagnosis was based on the clinical findings, and imaging methods, such Doppler ultrasonography, computed tomography (CT), magnetic resonance imaging (MRI) and angiography.

All the patients underwent surgical treatment.The pre operativeangioembolisation, intra operative external carotid artery ligation or clamping before tumour dissection were done for patients to reduce blood loss in shamblinIII, and selected patients of shamblin II group.

Figure 1:-Angiography showing vascular mass (carotid body tumour) at the carotid bifurcation (arrow).

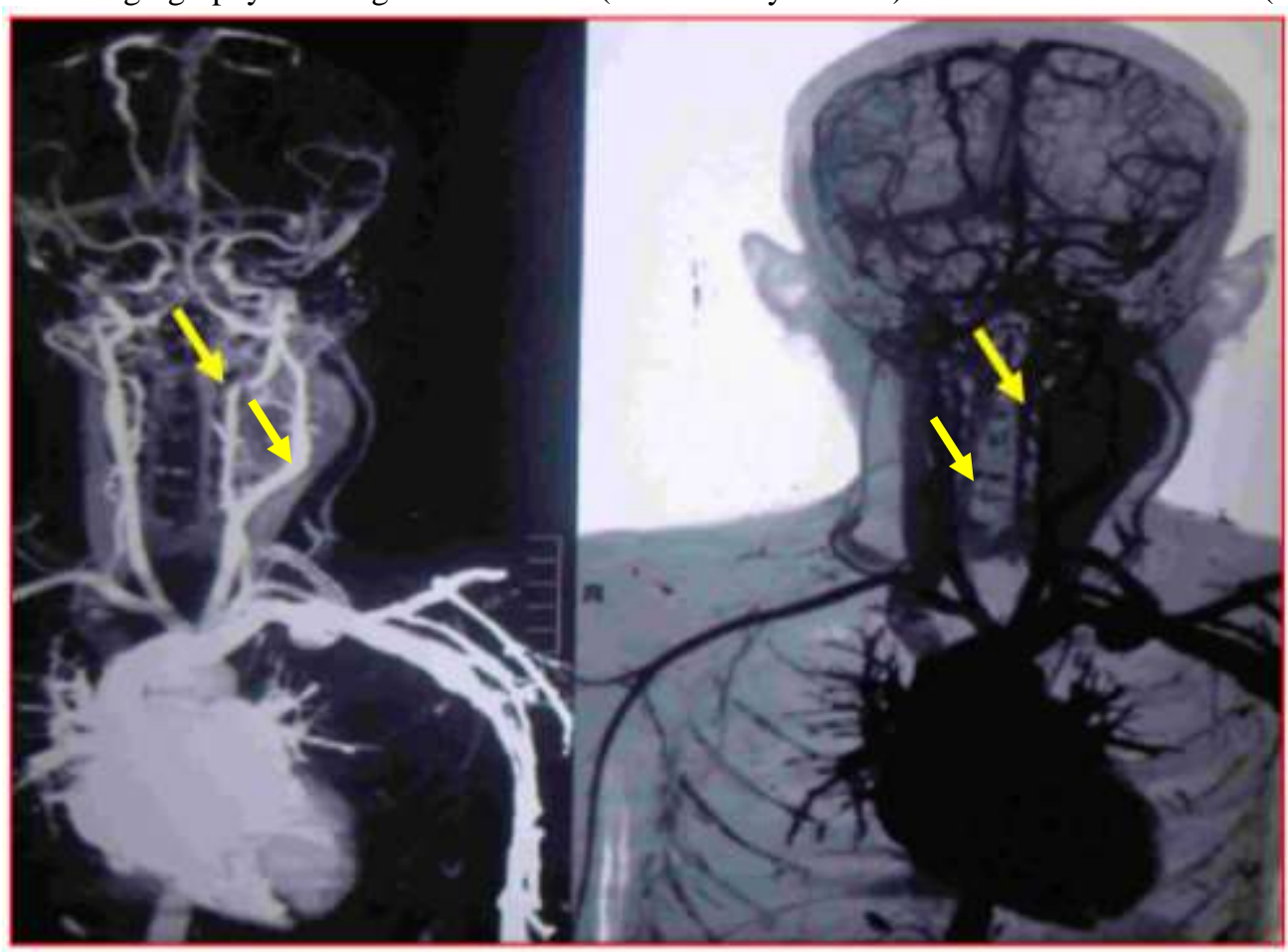


Figure 2:- Dissection of carotid body Tumor mass at the carotid bifurcation.( Arrow-CBT)

\section{Results:-}

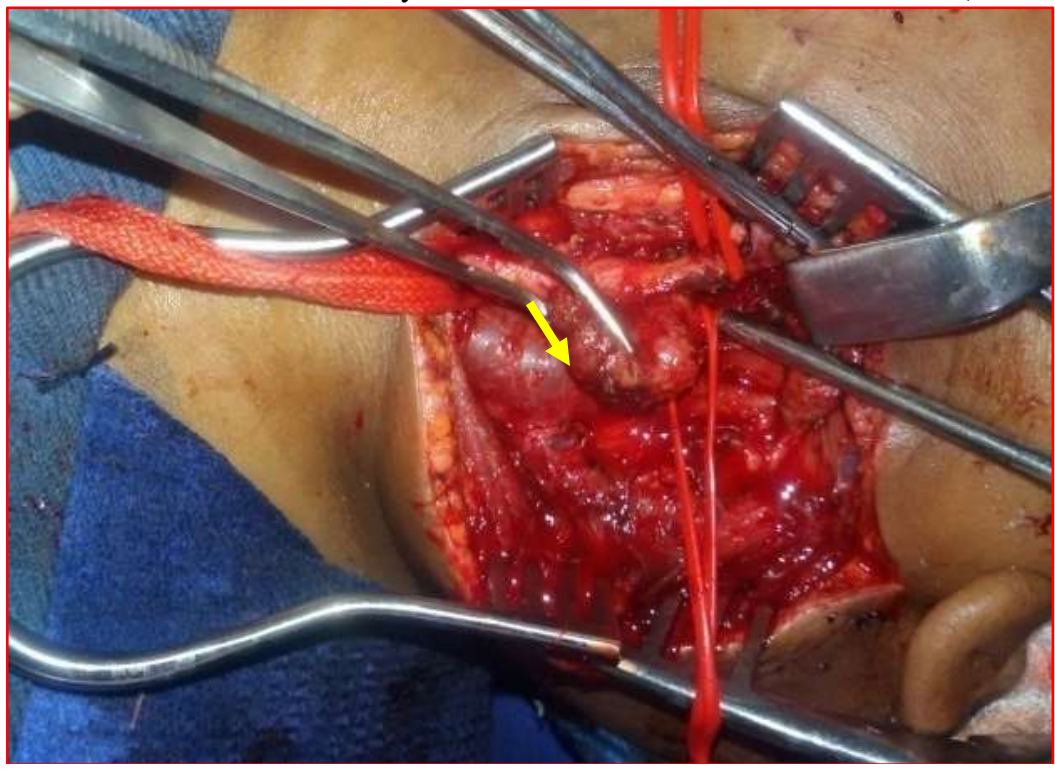

A total of 21 patients with age ranging from 13 to 60 years (median 45 years) with male (71\%)preponderance ( $\mathrm{M}: \mathrm{F}=2.5: 1)$ were diagnosed to have CBT in the study group. Local swelling was the commonest symptom ( $\mathrm{n}=21)$ presented in all patients, with other symptoms being hoarseness of voice $19 \%(\mathrm{n}=4)$, dysphagia $28.5 \%(\mathrm{n}=6)$, and ear/neck pain $33 \%(n=7)$. Left laterality was found in $76.2 \%$ of patients $(n=16)$, whereas $14.3 \%(n=3)$ of them were right sided with $9.5 \%(\mathrm{n}=2)$ bilateral cases.

Fifteen out of 21 patients (71.4\%) were classified as Shamblin's type II, with 2 of them (9.5\%) as type I and the remaining 4 patients $(19 \%)$ as type III CBTs. Thirteen patients $62 \%(\mathrm{n}-=13)$ underwent pre-operative angioembolisation. Twenty patients $(95.2 \%)$ underwent complete excision, whereas one patient underwent partial excision.

Operative site hematoma $33 \%(n=7)$ was the commonest post-operative complication encountered. Other complication include cranial nerve palsy $18 \%(\mathrm{n}=4)$, Wound infection $9.5 \%(\mathrm{n}=2)$ patients. None of our patient developed neurovascular deficit. Complete excision was done in twenty patients (95.2\%) except the one with partial excision (who had recurrence after 5 months) are asymptomatic with minimum of 6 months follow up.

Figure 3:- showing sex distribution

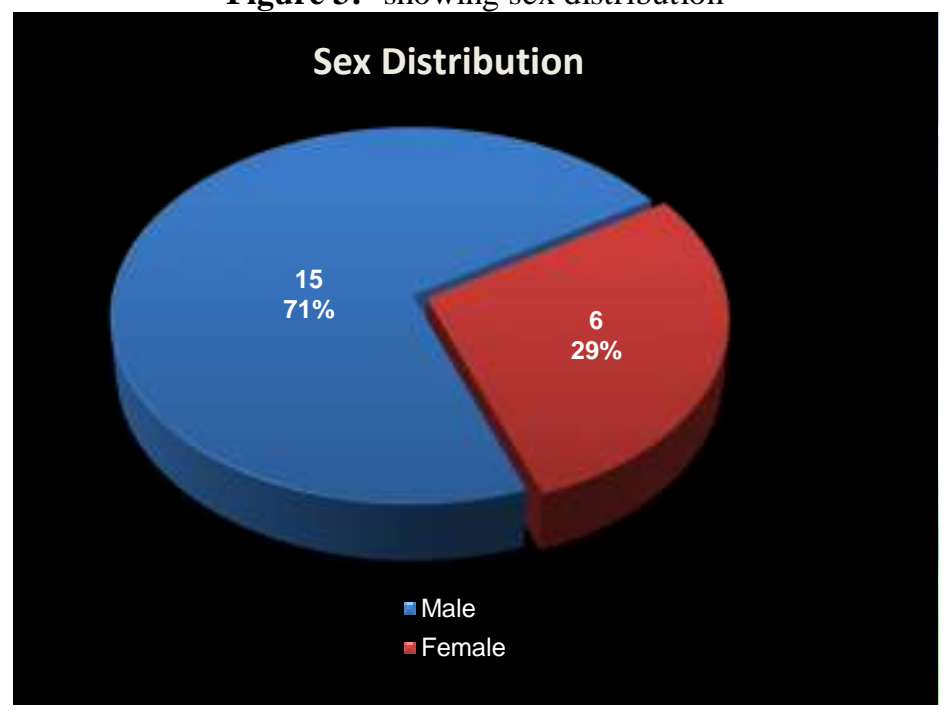


Figure 4:- showing age distribution

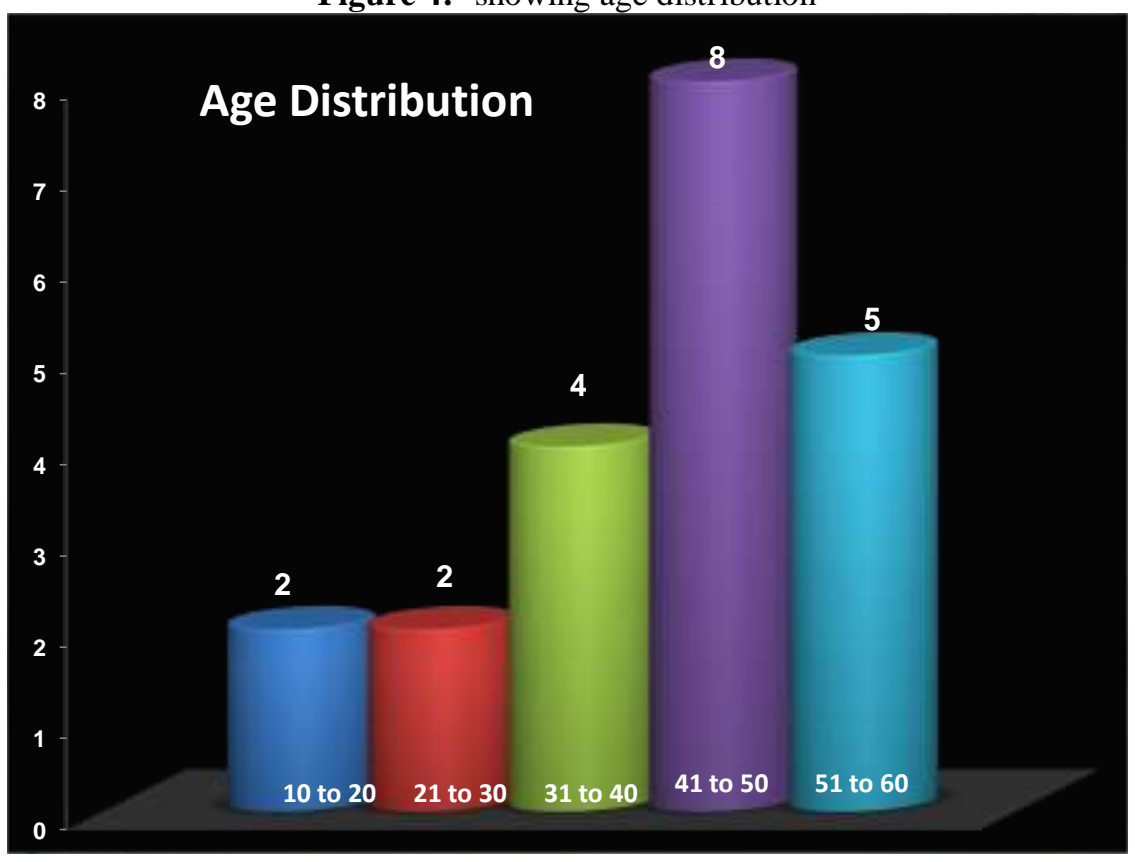

Figure 5:- showing clinical presentation

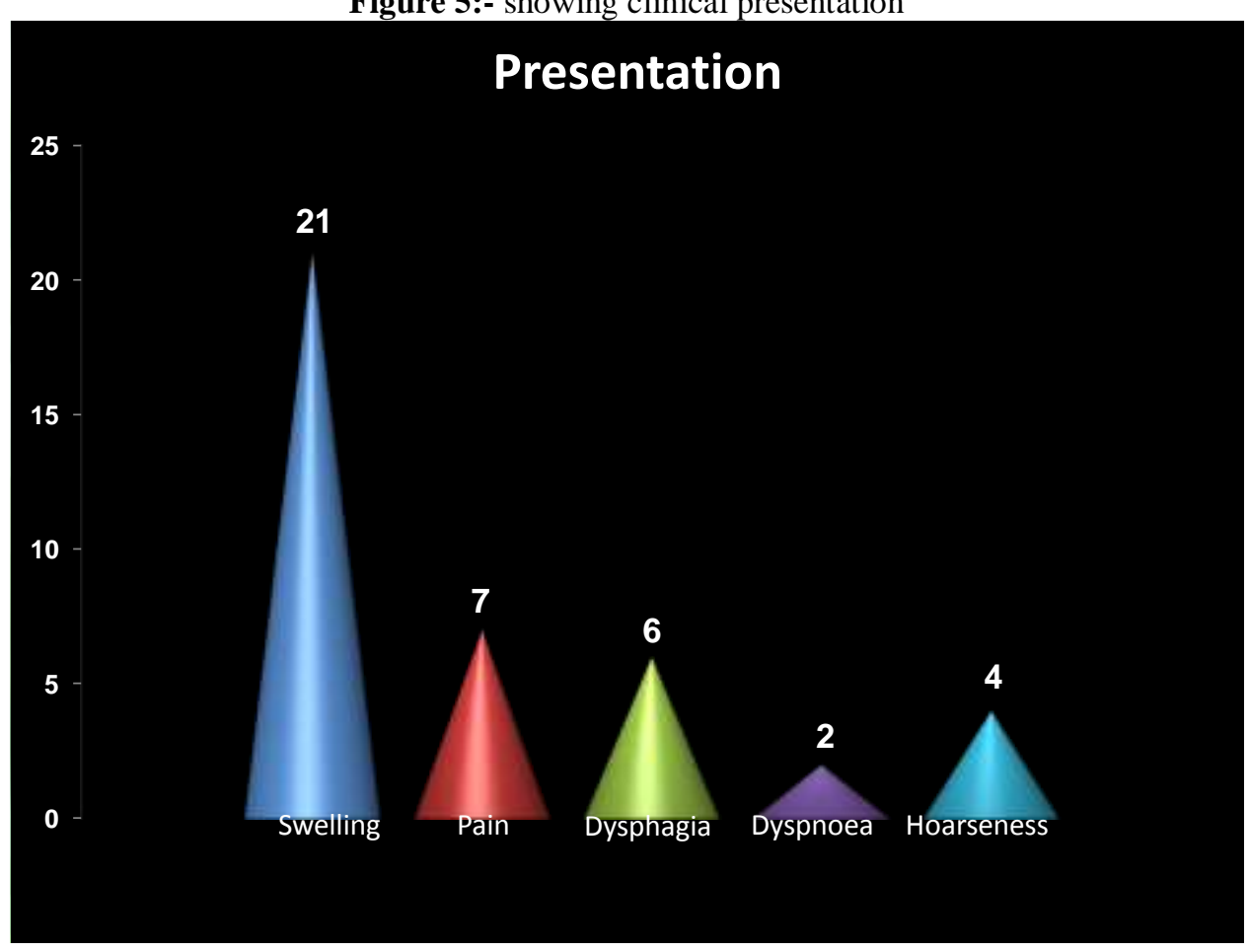

Table:-Outcome and complication according to shamblin classification

\begin{tabular}{|l|l|l|l|}
\hline & $\begin{array}{l}\text { shamblin } \\
\text { I }\end{array}$ & $\begin{array}{l}\text { shamblin } \\
\text { II }\end{array}$ & $\begin{array}{l}\text { Shamblin } \\
\text { III }\end{array}$ \\
\hline CLASSIFICATION & $2(9.5 \%)$ & $15(71 \% 0$ & $4(19 \%)$ \\
\hline EXCISION & TOTAL & TOTAL & $\begin{array}{l}\text { 3TOTAL,ONE } \\
\text { PARTIAL }\end{array}$ \\
\hline ANGIOEMBOLISATION & 0 & 9 & 4 \\
\hline
\end{tabular}




\begin{tabular}{|c|c|c|c|c|c|}
\hline $\begin{array}{l}\text { ICA } \\
\text { RECONSTRUCTION }\end{array}$ & WITH & 0 & 0 & 3 & \\
\hline ICA LIGATION & & 0 & 0 & 1 & \\
\hline HAEMATOMA & & 1 & 2 & 4 & \\
\hline WOUND INFECTION & & 0 & 1 & 1 & \\
\hline STROKE/TIA & & 0 & 0 & 0 & \\
\hline CRANIAL NERVE PALSY & & 0 & 1 & $\begin{array}{l}3(7 \mathrm{TH}, 10 \mathrm{TH}, 12 \mathrm{TH} \\
\text { NERVES) }\end{array}$ & CRANIAL \\
\hline RECURRENCE & & 0 & 0 & 1 & \\
\hline
\end{tabular}

\section{Discussion:-}

The carotid body contains chemoreceptors that are sensitive to hypoxia. The incidence of this tumor is greater at higher altitudes, due to the chronic hypoxia. ${ }^{11}$ There have been several reports in the literature mentioning presenceof significant predominance in female, although ur series showed predominance of males $(71 \%)$. The paramount clinical characteristic is a pulsatile cervical mass. As reported in the literature, the diagnosis can be confused even with benign conditions, including congenital branchial cysts or other benign conditions. ${ }^{12}$

CT scans or magnetic resonance imaging are better for identifying the dimensions and anatomical correlations of the tumor.The main diagnostic tool is arterial studies such as contrast angiography, computed angiotomography or magnetic resonance angiography (MRA), thereby. The MRA seems to be preferable nowadays. ${ }^{13}$

In the literature, the best treatment is considered to be surgical, with dissection of the tumor in the sub-adventitial avascular plane of the artery. Large tumors (Shamblin II and III) may require vascular procedures, including repairs, sutures and resections of the arterial segments. ${ }^{12}$ At times, it may be necessary to sacrifice the external carotid artery, perform anastomosis between the internal and common carotid arteries or undertake vascular reconstruction with grafts. ${ }^{14}$.Two of our cases underwent internal carotid artery primary repair(ICA), one patient underwent ICA reconstruction with synthetic graft and one patient underwent ICA ligation all of which belongs to Shamblin III group $^{15}$ due to.

Conservative treatment should be reserved for patients who are not suitable for surgery, such as clinically unstable patients, extremely old patients or those with the certainty of stroke. Furthermore, studies have shown that this therapeutic method is ineffective in these tumors. ${ }^{16}$ None of our patient managed conservatively ,one of our patient underwent radiotherapy for residual recurrent lesion.

Embolization is another therapeutic method, usually done prior to the surgical procedure, as an attempt to decrease intraoperative bleeding. ${ }^{3,4}$.In our series, cranial nerve deficits occurred in three patients, involving the VII, X and XII pairs which is concordant with other series. Power et al. demonstrated that preoperative embolization may have some benefits for the surgical approach, especially relating to surgical bleeding, but the patients that they followed up did not present any differences in definitive neurological sequelae.,12

Although our series did not have any cases of malignant chemodectoma, it is important to mention that the malignant potential has been reported to be around $2-6 \%$ in the literature, most frequently with metastasis to regional lymph nodes. ${ }^{15}$. Finally, although we did not have any cases of mortality, the literature mentions a mortality rate of less than $2 \%{ }^{4}$.

\section{Conculsion:-}

Shamblin III had a high risk of postoperative neurovascular complications. Therefore, early detection and prompt surgical resection of CBTs will decrease surgical morbidity.

\section{References:-}

1. Persky MS, Setton A, Niimi Y, Hartman J, Frank D, Berenstein A. Combined endovascular and surgical treatment of head and neck paragangliomas: a team approach. Head Neck. 2002 May;24(5):423-31.

2. Williams MD, Phillips MJ, Nelson WR, Rainer WG. Carotid body tumor. Arch Surg. 1992;127(8):963-7; discussion 967-8.

3. Arya S, Rao V, Juvekar S, Dcruz AK. Carotid body tumors: objective criteria to predict the Shamblin group on MR imaging. AJNR Am J Neuroradiol. 2008;29(7):1349-54. 
4. Shamblin WR, ReMine WH, Sheps SG, Harrison EG Jr. Carotid body tumor (chemodectoma). Clinicopathologic analysis of ninety cases. Am J Surg. 1971;122(6):732-9.

5. Gordon-Taylor G. On carotid tumours. Br J Surg. 1940 Oct;28(110): 163-72.

6. Hallett JW Jr, Nora JD, Hollier LH, Cherry KJ Jr, Pairolero PC. Trends in neurovascular complications of surgical management for carotid body and cervical paragangliomas: a fifty-yr experience with 153 tumors. J Vasc Surg. 1988 Feb;7(2):284-91.

7. Westerband A, Hunter GC, Cintora I, Coulthard SW, Hinni ML, Gentile AT, et al. Current trends in the detection and management of carotid body tumors. J Vasc Surg. 1998 Jul;28(1):84-92.

8. Zhang TH, Jiang WL, Li YL, Li B, Yamakawa T. Perioperative approach in the surgical management of carotid body tumors. Ann Vasc Surg. 2012;26(6):775-82.

9. Power AH, Bower TC, Kasperbauer J, et al. Impact of preoperative embolization on outcomes of carotid body tumor resections. J Vasc Surg. 2012;56(4):979-89.

10. Shamblin WR, ReMine WH, Sheps SG, Harrison EG Jr. Carotid body tumor (chemodectoma): clinicopathologic analysis of ninety cases. Am J Surg. 1971 Dec;122(6):732-9.

11. Rodriguez-Cuevas H, Lau I, Rodriguez HP. High-altitude paragangliomas: diagnostic and therapeutic considerations. Cancer. 1986;57(3):672-6.

12. Williams MD, Phillips MJ, Nelson WR, Rainer WG. Carotid body tumor. Arch Surg. 1992;127(8):963-7; discussion 967-8.

13. Arya S, Rao V, Juvekar S, Dcruz AK. Carotid body tumors: objective criteria to predict the Shamblin group on MR imaging. AJNR Am J Neuroradiol. 2008;29(7):1349-54.

14. Anand VK, Alemar GO, Sanders TS. Management of the internal carotid artery during carotid body tumor surgery. Laryngoscope. 1995;105(3 Pt 1):231-5.

15. Mitchell RO, Richardson JD, Lambert GE. Characteristics, surgical management, and outcome in 17 carotid body tumors. Am Surg. 1996;62(12):1034-7.

16. Sanghvi VD, Chandawarkar RY. Carotid body tumors. J SurgOncol. 1993;54(3):190-2. 